\title{
Kompozit Malzemelerin Delinmesinde Matkap Nokta Açısının ve ÇCKNT'lerin Etkisi
}

\author{
${ }^{* 1}$ Ferhat Ceritbinmez and ${ }^{2}$ Ahmet Yapıcı \\ *1 Haier Europe - Candy Hoover Group, Eskișehir, Türkiye \\ ${ }^{2}$ İskenderun Teknik Üniversitesi, Makina Mühendisliği Bölümü, Hatay, Türkiye
}

\begin{abstract}
Özet :
Endüstride malzemelerin cıvata, perçin ve pim bağlantıları ile montajlanması veya üzerlerine delikler oluşturmak için matkap ile delme yöntemi kullanılmaktadır. Kompozit malzemelerin delinmesi esnasında çapaklanma, delaminasyon ve malzeme yarılması görülmektedir. İşleme parametreleri, delinen malzemenin mekanik özellikleri ve matkap nokta açısı delik kalitesini etkileyen en önemli faktörlerdir. Bu çalışmada cam elyaf takviyeli polimer (CETP) kompozit plakalara nano boyutta katkı maddesi eklenmesinin mekanik özelliklerine ve matkap yöntemi ile delinmesine etkisi araştırılmıştır. Tabakalı cam elyaf kompozit malzemelere nano partikül ilavesinin malzemenin dayanımında etkili bir rol oynadığı ve delik kalitesine etki ettiğgi görülmüştür. Sabit fener mili devri değerleri kullanılarak yapılan delme işlemlerinde; tezgah ilerlemesi arttıkça çapaklanmanın arttığı, matkap nokta açısının artması ile delik çapının arttığ tespit edildi. $90^{\circ}$ ve $140^{\circ}$ açılı matkaplar kullanılarak delinen deliklerin çıkış kısımlarında epoksi tabakasının blok şeklinde cam elyaf tabakasından ayrıldığı görüldü.
\end{abstract}

Anahtar Kelimeler: CETP, ÇCKNT, İşlenebilirlik, Matkap Nokta Açısı

\section{The Effect Of Drill Point Angle And MWCNTs doped In Drilling Of Composite Materials}

\begin{abstract}
:
In the industry, drilling method is used to both assemble materials with bolts, rivets and pin joints and to create holes on them. Burring, delamination and material splintering are observed during the drilling of composite materials. Machining parameters, mechanical properties of the drilled material and drill point angle are the most important factors affecting the hole quality. In this study, the effect of the addition of nano-sized additive to glass fiber reinforced composite plates and the effect of these materials on drillability were investigated. It has been observed that the addition of nanoparticles to the laminated glass fiber composite materials plays an effective role in the strength of the material and affects the quality of the holes. Drilling operations which used by constant spindel revolation, if feed rate increases, burring also increases. It is also clear that drilling point angle increase caused drilling hole diameter increment. It was seen that the epoxy layer was separated from the block-shaped glass fiber layer at the outlet of the holes drilled using $90^{\circ}$ and $140^{\circ}$ angle drills.
\end{abstract}

Key words: GFRP, MWCNTs, Machinability, Drill Point Angle

*Corresponding author: Address: Haier Europe - Candy Hoover Group, Organize Sanayi Bölgesi 8.Cd. No:1 26110, Eskişehir, TURKEY. E-mail address: ferhatceritbinmez@gmail.com, Phone: +90222360650 


\section{Giriş}

Gelişen teknoloji, rekabet ve kalite ihtiyaçlarından kaynaklanan malzeme arayışı, kompozit malzemelerin keşfedilip, geliştirilmesini sağlamıştır. Yüksek mukavemet ve sertlik-ağırlık oranı, düşük yoğunluk, uzun yorulma ömrü, yüksek korozyon ve aşınma dirençleri onları birçok endüstride kullanılan en genel amaçlı malzemelerden biri yapar [1-9]. Önemli olma potansiyeline sahip başka tür kompozitler gelecekteki nanokompozitlerdir [10]. Havacılık, otomotiv, denizcilik ve kimya sanayisinde nanokompozit kullanımı giderek artmaktadır [11]. Nano parçacık takviyesi ile daha hafif ve daha güçlü malzemeler elde edilebilmektedir. Çok cidarlı karbon nanotüplerin (ÇCKNT) üstün mekanik özellikleri, onları kompozit malzemelere takviye için tercih edilen dolgu maddesi haline getirmektedir [12-13]. Dayanımı yüksek kompozit malzemelerin endüstride kullanım yerine montajlanabilmesi için bazı talaşlı veya talaşsız imalat teknikleri kullanılmaktadır, bunların en yaygın olanı matkap ile delme yöntemidir [14-16]. Matkap ile delme esnasında kompozit yapılarda çapaklanma, delaminasyon, parçalanma vb. hasarlar görülmektedir. Literatürde farklı matriks ve fiber malzemelerden oluşan kompozit malzemelerin delinmesi esnasında karşılaşılan problemler çeşitli yönleri ile ele alınmıştır. Liu ve arkadaşları kompozit laminatların mekanik delinmesi hakkında araştırmalar yaparak; delme ucu geometrisi, delme kaynaklı delaminasyon, itme kuvveti ve takım aşınması konularını inceleyerek cam elyafların ve özellikle karbon elyafların delme işlemlerinde yüksek düzeyde takım aşınmasına sebep olduğunu, kaplamalı karbür takımlar ve PCD (Polycrystall Diamond) takımların, delme sırasında takım aşınması ve takım ömrü açısından iyi sonuçlar verdiğini bildirmiştir [16]. Davim ve arkadaşları karbon fiber takviyeli kompozitlerin matkap ile delinmesinde kesme parametrelerinin etkilerini incelemiştir [17]. Abrao ve arkadaşları cam elyaf takviyeli epoksi kompozitin delinmesinde kesici takım geometrisinin ve malzemesinin itme kuvveti ve delaminasyon üzerindeki etkisini araştırmışlardır [18]. Tsao ve arkadaşları karbon fiber takviyeli kompozit malzemelerin helisel matkap ile delinmesinde matkap aşınmasının yol açtığ delaminasyonu kapsamlı bir şekilde analiz etmiş, artan aşınma ve itme kuvveti nedeniyle daha yüksek delaminasyon olduğunu vurgulamıştır [19]. Hocheng ve Tsao testere matkabı, karot matkabı ve kademeli matkap gibi çeşitli matkap tiplerinin kompozit malzemelerde delaminasyona etkisini analiz ederek çeşitli özel matkaplar için delaminasyon başlangıcındaki kritik bask1 kuvvetini matematiksel olarak tahmin ederek geleneksel helisel matkapla karşılaştırmışlardır [20]. Mohan ve arkadaşları cam elyaf takviyeli plastik (GFRP) kompozit malzemelerin delinmesinde karşılaşılan delaminasyonu Taguchi metodu ve Anova ile analiz ederek; ilerleme oranı, kesme hızı ve malzeme kalınlığının delaminasyona etki ettiğini fakat en büyük etkiyi ilerleme oranının yaptığını bildirmişlerdir [21]. Davim, Reis ve Antonio; CFRP malzemesinin semente karbür (K10) matkap kullanılarak delinmesinde, kesme hizı ve ilerleme hızı ile belirli kesme basıncı, itme kuvveti, hasar faktörü ve yüzey pürüzlülüğü arasında bir ilişki kurmak için Taguchi tekniklerine dayanan deneyler yaparak varyans analizi (ANOVA) ile sonuçlar elde etmiştir [22]. Palanikumar ve arkadaşları CETP malzemelerin $85^{\circ}, 115^{\circ}, 130^{\circ}$ nokta açısına sahip semente karbür matkaplar kullanılarak delinmesini varyans analizi (ANOVA) ile analiz etmiş; fener mili devri arttıkça delaminasyonun azaldığını, düşük fener mili devri ve yüksek ilerleme değerlerinde delaminasyonun arttığını rapor etmişlerdir. CETP kompozitlerinin delinmesindeki delaminasyon faktörünü en aza indirmek için daha yüksek hız, düşük besleme ve nokta açısı kombinasyonunun gerekli olduğunu vurgulamışlardır [23]. Yapılan çalışmalar ilerleme oranının, delme işleminde delaminasyon, itme kuvveti ve takım aşınmasına en büyük 
etkiyi yaptığını göstermektedir. Genel olarak, düşük ilerleme hızı ve yüksek kesme hızı kullanımının takım ömrünü uzatarak giriş ve çıkış delaminasyonunu azaltığı rapor edilmiştir [1618, 21-22]. Bu çalışmada cam elyaf takviyeli kompozit tabakalara ÇCKNT takviyesi yapılarak daha iyi mekanik özelliklere sahip nano kompozit elde edildi. Üretilen kompozitler farklı nokta açısına sahip HSS matkaplar ve değişken fener mili devri, ilerleme oranı parametreleri ile delinerek; delik kalitesi, delaminasyon, çapaklanma, parçalanma konuları incelenmiştir. Nano partiküllerin epoksi ve cam elyafları bir arada tutma eğilimi içinde olduğu; matkap ucu açısının yüksek olmasından kaynaklı itme kuvveti ile delik çıkış kısımlarında epoksi tabakasının blok şeklinde elyaf tabakasından ayrıldığı gözlemlendi.

\section{Materyal ve yöntem}

\subsection{CETP ve \% 0.1 ÇCKNT katkılı kompozit tabaka üretimi}

Karbon nanotüp katkılı ve katkısız cam elyaf takviyeli polimer (CETP) kompozit tabakalar vakum infüzyon yöntemi kullanılarak $300 \mathrm{~mm}$ x $300 \mathrm{~mm}$ ebatlarında üretildi. Hexion MGS LR160 reçine ve MGS LH160 sertleştirici karışımı ağırlıkça 4:1 oranında hazırlandı. Fiber malzeme olarak her üretim için $0 / 90^{\circ}$ fiber oryantasyonuna sahip 8 tabaka düz örgülü cam elyafları kullanıldı. Kullanılan katkı maddelerinin ve matriks malzemenin mekanik özellikleri Tablo 1 de görülmektedir. ÇCKNT katkılı kompozit malzemelerin üretiminde hazırlanan reçine miktarının ağırlıkça \% 0.1 oranında nano partikül ilavesi yapıldı. Vakum infüzyon sonrası kompozit tabakalar $23^{\circ} \mathrm{C}$ de 24 saat kürlendi.

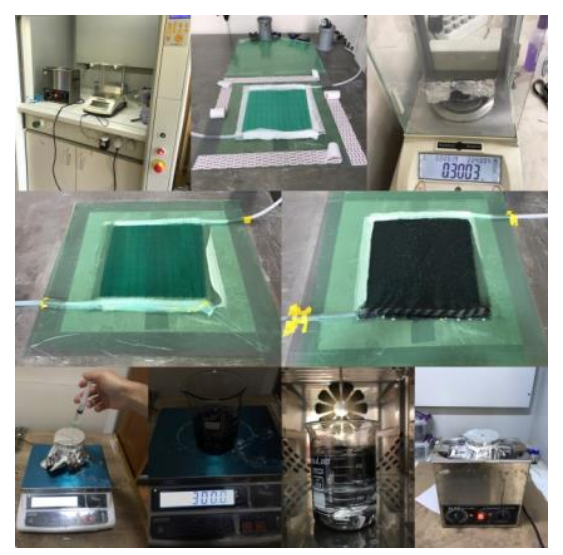

Şekil 1. Kompozit tabaka imalatı

Tablo 1. Katk1 maddelerinin ve matriks malzemenin mekanik özellikleri

\begin{tabular}{|c|c|c|c|c|c|}
\hline \multicolumn{2}{|c|}{$\begin{array}{c}\text { Cam Elyaf Kumaş Düz Örgü } \\
{[0 / 90] s}\end{array}$} & \multicolumn{2}{|c|}{$\begin{array}{l}\text { Saf Reçine Mekanik Özellikleri } \\
\text { Kürleme: } 24 \mathrm{~s}, 23^{\circ} \mathrm{C}+15 \mathrm{~s}, 60^{\circ} \mathrm{C}\end{array}$} & \multicolumn{2}{|c|}{$\begin{array}{c}\text { Karbon Nanotüp saflık }>\% 90 \\
\text { (Siyah)/COOH Fonksiyonlu CNTs }\end{array}$} \\
\hline Fiber çap $1(\mu \mathrm{m})$ & 7 & Yoğunluk $\left(\mathrm{g} / \mathrm{cm}^{3}\right)$ & $1.18-1.2$ & Sıkışık yoğunluk $\left(\mathrm{g} / \mathrm{cm}^{3}\right)$ & 0.14 \\
\hline Yoğunluk $\left(\mathrm{g} / \mathrm{cm}^{3}\right)$ & 2.6 & Eğilme gerilmesi (MPa) & 40 & Gerçek yoğunluk (g/c & 2.1 \\
\hline Çekme gerilmesi (MPa) & 3.5 & . & $70-80$ & Diş Ç & $10-30$ \\
\hline Çek & 72 & Elastisite Modülü (GPa) & $3.2-3.5$ & İç Çap (nm) & $5-10$ \\
\hline Kopma uzama (\%) & 4.8 & Kopma uzama (\%) & $5.0-6.5$ & Uzunluk $(\mu \mathrm{m})$ & $10-30$ \\
\hline
\end{tabular}




\section{2. Çekme Testi}

Üretimi tamamlanan kompozit tabakalardan $250 \mathrm{~mm}$ x $25 \mathrm{~mm}$ ebatlarında beşer adet çekme testi numunesi dekopaj testere kullanılarak hazırland1. Üniversal çekme testi cihazı, epsilon ekstansometre (Model:3542-050M-100-ST), nikon SMZ 745T stereo mikroskop kullanılarak ASTM D3039 / D3039M. standardına göre çekme testleri tamamlandı (Şekil.2).

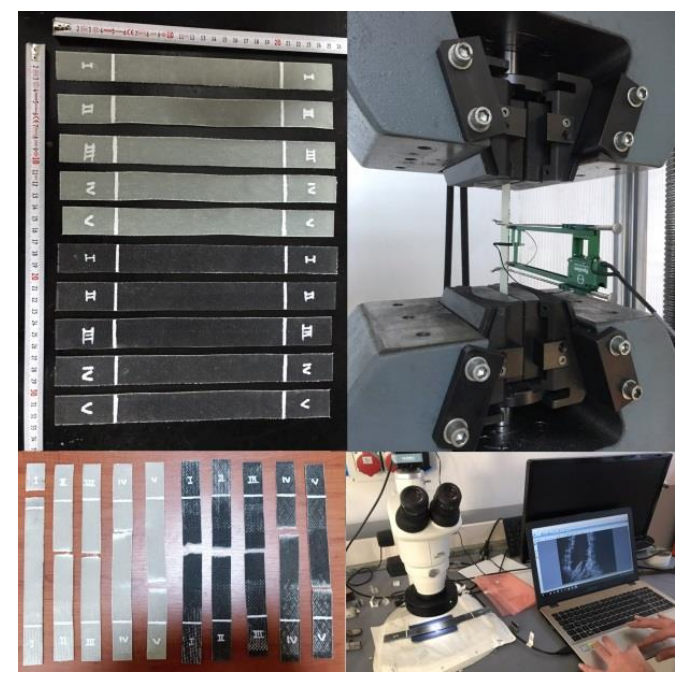

Şekil 2. Çekme testi ekipmanları ve numune analizi

\subsection{Yakma ve Yoğunluk Testleri}

Kompozit yapıların yoğunluk ve hacim oranlarının tespiti için her tabakadan dört adet $25 \mathrm{~mm} \mathrm{x}$ $25 \mathrm{~mm}$ ölçülerinde numune hazırlanarak 1sıl işlem firınında yakıldı. Epoksinin numunelerden uzaklaştırılması sonrası ve test öncesi tüm numuneler HZK-110FA Serisi $0.0001 \mathrm{~g}$ hassasiyete sahip terazi ile tartıldı. Elyaf, matriks hacim oranlarının ve malzeme yoğunluklarının belirlenmesinde ASTM D317 standardı ve Arşimet prensibinden faydalanıldı (Şekil.3).

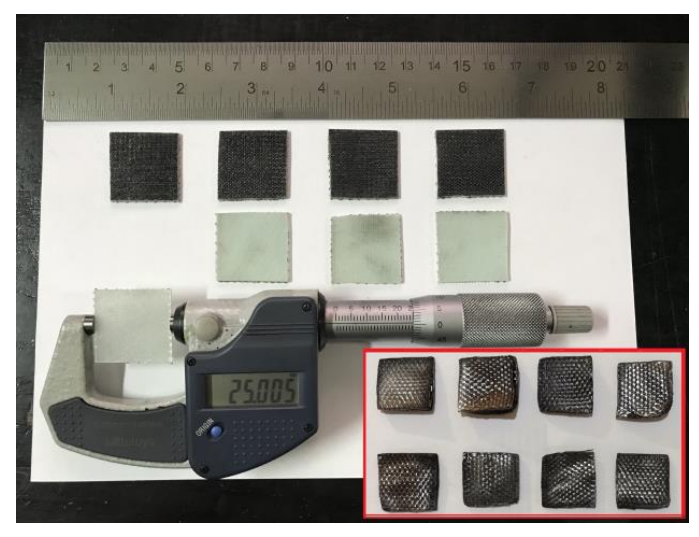

Şekil 3. Yakma testi ve yoğunluk hesaplamaları 


\subsection{Sertlik (Barcoll) Testi}

Her bir kompozit tabakanın farklı bölgelerinden toplam 22 adet ölçüm alınarak ortalama yüzey sertliği tespit edildi. Barcol impressor 934-1 cihazı kullanılarak ASTM D2583 standardına göre ölçümler yapıldı (Şekil.4).

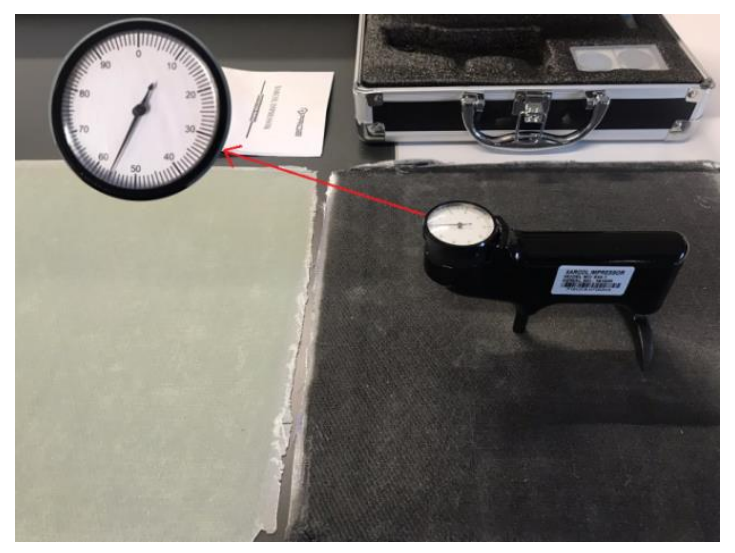

Şekil 4. Barcoll sertlik ölçümü

\subsection{Açılı Matkap Bileme}

Delme işlemi öncesi 200-250 HB (Brinell Hardness) sertliğine sahip HSS (High Speed Steel) matkapların kesme uçları, EDG-213N kesici bileme tezgahında $90^{\circ}, 118^{\circ}, 140^{\circ}$ olacak şekilde bilendi (Şekil.5). Yaklaşık $600^{\circ} \mathrm{C}$ sıcaklıklara kadar susuz çalışabilen ve dayanımlarını kaybetmeyen matkaplar ile su kullanılmadan delik delme işlemi yapıldı.

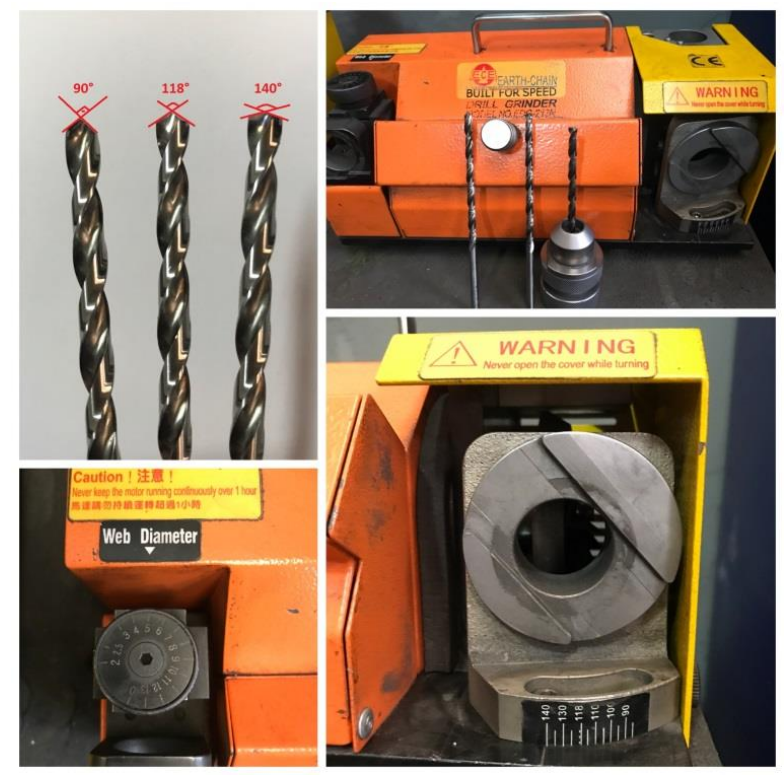

Şekil 5. Açılı Matkap Bileme Makinası(EDG-213N) 


\subsection{CNC Tezgahında Matkap İle Delme Analizleri}

Makino S33 model CNC tezgahına özel mengene ile sabitlenen kompozit deney numunelerine $\varnothing 5 \mathrm{~mm}$ çapında $90^{\circ}, 118^{\circ}, 140^{\circ}$ kesme ağzı açısına sahip HSS matkaplar kullanılarak, gagalama yapılmadan, soğutucu kullanılmadan direk kompozit tabakaya dalarak delme işlemi yapıldı (Şekil.6). $1000 \mathrm{dev} /$ dak fener mili devri sabit tutularak 200, 600, $1000 \mathrm{~mm} /$ dak ilerleme değerleri ile delikler delindi.

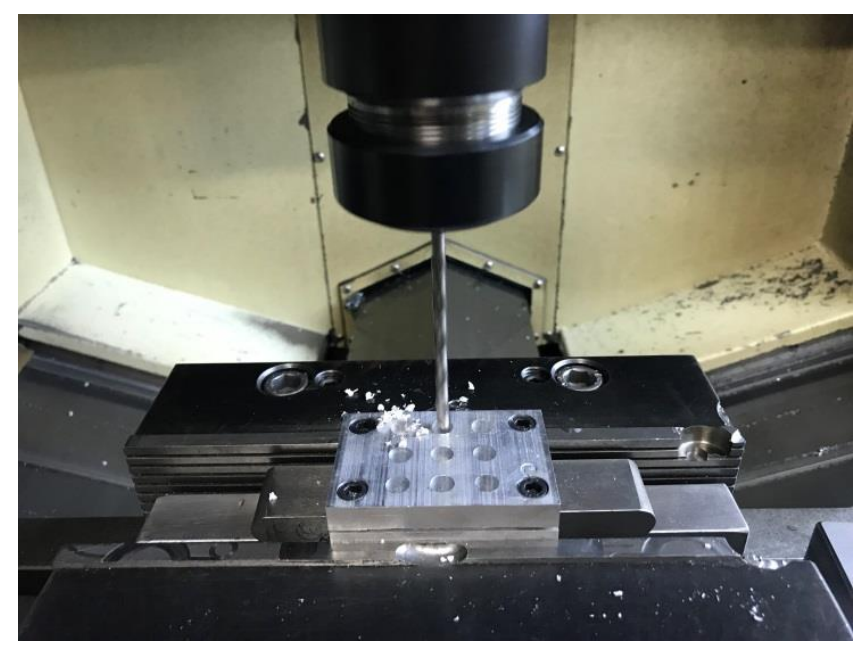

Şekil 6. Makino S33 CNC Tezgahında Delik Delme İşlemi

Delik kalitesini arttırmak ve delaminasyonu azaltmak için her bir deney numunesi, 5083 alüminyum malzemeden tasarlanmış özel aparatlar yardımı ile mengeneye bağlandı. Destek plakası görevi gören aparat ile matkap ucunun kompozit plakaya sehim yaptırmasının önüne geçildi [16].

\section{Deneysel sonuçlar ve tartışma}

\subsection{Mekanik özellikler ve çekme testi sonuçlart}

Yapılan ölçümler neticesinde Tablo 2 de görüldüğü gibi ÇCKNT katkısı ile daha hafif ve dayanımı yüksek malzemeler elde edildi.

Tablo 2. \% 0.1ÇCKNT katkılı ve katkısız kompozit malzemelerin mekanik özellikleri

\begin{tabular}{|c|c|c|c|c|c|c|}
\hline $\begin{array}{c}\text { Malzeme } \\
(\% \text { 0.1 ÇCKNT) }\end{array}$ & $\begin{array}{c}\text { Yoğunluk } \\
\left(\mathrm{g} / \mathrm{cm}^{3}\right)\end{array}$ & $\begin{array}{c}\text { Elastisite } \\
\text { Modülü } \\
(\mathbf{G P a})\end{array}$ & $\begin{array}{c}\text { Maksimum } \\
\text { Kuvvet } \\
(\mathbf{k N}) \\
\end{array}$ & $\begin{array}{c}\text { Maks.Çekme } \\
\text { Gerilmesi } \\
\text { (Mpa) }\end{array}$ & $\begin{array}{c}\text { Kopma } \\
\text { Uzama } \\
(\%) \\
\end{array}$ & $\begin{array}{c}\text { Poison } \\
\text { oranı } \\
(\mathbf{m m} / \mathbf{m m}) \\
\end{array}$ \\
\hline Saf Kompozit & 1.62 & 22.97 & 13.74 & 338.811 & 2.16 & 0.14 \\
\hline Katkılı Kompozit & 1.59 & 24.99 & 14.53 & 364.303 & 1.29 & 0.15 \\
\hline
\end{tabular}




\subsection{Yakma, yoğunluk ve barcoll testi}

Tablo 3. ve 4. katkılı kompozitin fiber hacim oranı, başluk hacim oranı ve yüzey sertliğinin arttığını; yoğunluk ve matriks hacim oranın azaldığını göstermektedir. Nano partikül katkısının malzemenin mekanik özelliklerine etki ettiği tespit edilmiştir.

Tablo 3. Kompozit malzemelerin fiber-matriks-boşluk hacim oranları

\begin{tabular}{lcc}
\hline Spesifıkasyon & Saf Kompozit & Katkılı Kompozit \\
\hline Yoğunluk $\left(\mathrm{gr} / \mathrm{cm}^{3}\right)$ & 1.62 & 1.59 \\
Fiber hacim oranı \% & 40.47 & 41.88 \\
Matriks hacim oranı \% & 49.96 & 45.12 \\
Boşluk hacim oranı \% & 9.30 & 12.97 \\
\hline
\end{tabular}

Tablo 4. Saf ve katk1lı kompozitlerin sertlik değerleri

\begin{tabular}{lcc}
\hline Malzeme (\% 0.1 ÇCKNT) & Test Sayısı & Barcol Sertlik \\
\hline Saf Kompozit & 22 & 48 \\
Katkı1ı Kompozit & 22 & 56 \\
\hline
\end{tabular}

\subsection{Test parametreleri ve sonuçları}

Delme operasyonlarında kullanılan işleme parametreleri ve delik kalitesi değerleri Tablo 5' te gösterilmiştir. Farklı işleme parametreleri ile yapılan kesme işlemlerinde delaminasyon ve çapaklanma tespit edildi; delik çevresinde sertlik değişimine veya parçalanmaya rastlanmadı.

Tablo 5. Test parametreleri ve sonuçları

\begin{tabular}{|c|c|c|c|c|c|c|c|c|c|c|}
\hline \multirow[b]{2}{*}{$\begin{array}{l}\text { Deney } \\
\text { No }\end{array}$} & \multirow[b]{2}{*}{$\begin{array}{l}\text { Takım } \\
\text { Çapı } \\
\text { (mm) }\end{array}$} & \multirow[b]{2}{*}{$\begin{array}{c}\text { Nokta } \\
\text { Açıs1 } \\
\text { (derece) }\end{array}$} & \multirow[b]{2}{*}{$\begin{array}{c}\text { Fener Mili } \\
\text { Devri } \\
\text { (dev/dak) }\end{array}$} & \multirow[b]{2}{*}{$\begin{array}{c}\text { İlerleme } \\
\text { Oranı } \\
\text { (mm/dak) }\end{array}$} & \multirow[b]{2}{*}{$\begin{array}{c}\text { Malzeme } \\
(\% 0.1 \text { ÇCKNT) }\end{array}$} & \multicolumn{5}{|c|}{ Delik Kalitesi } \\
\hline & & & & & & $\begin{array}{l}\text { Delik } \\
\text { Çap1 } \\
(\mathrm{mm})\end{array}$ & Delaminasyon & Parçalanma & Çapaklanma & $\begin{array}{c}\text { Sertlik } \\
\text { Değeri } \\
\text { (Ba) }\end{array}$ \\
\hline \multirow{2}{*}{1} & \multirow{2}{*}{5} & \multirow{2}{*}{90} & \multirow{2}{*}{1000} & \multirow{2}{*}{200} & saf kompozit & 4.92 & yok & yok & yok & $42-48$ \\
\hline & & & & & katk1lı kompozit & 4.95 & yok & yok & yok & $50-56$ \\
\hline \multirow{2}{*}{2} & \multirow{2}{*}{5} & \multirow{2}{*}{90} & \multirow{2}{*}{1000} & \multirow{2}{*}{600} & saf kompozit & 4.9 & var & yok & var & $42-48$ \\
\hline & & & & & katk1lı kompozit & 4.9 & yok & yok & var & $50-56$ \\
\hline \multirow{2}{*}{3} & \multirow{2}{*}{5} & \multirow{2}{*}{90} & \multirow{2}{*}{1000} & \multirow{2}{*}{1000} & saf kompozit & 4.85 & var & yok & var & $42-48$ \\
\hline & & & & & katk1lı kompozit & 4.87 & var & yok & var & $50-56$ \\
\hline \multirow{2}{*}{4} & \multirow{2}{*}{5} & \multirow{2}{*}{118} & \multirow{2}{*}{1000} & \multirow{2}{*}{200} & saf kompozit & 4.95 & yok & yok & yok & $42-48$ \\
\hline & & & & & katk1lı kompozit & 4.96 & yok & yok & yok & $50-56$ \\
\hline \multirow{2}{*}{5} & \multirow{2}{*}{5} & \multirow{2}{*}{118} & \multirow{2}{*}{1000} & \multirow{2}{*}{600} & saf kompozit & 4.94 & yok & yok & var & $42-48$ \\
\hline & & & & & katk1lı kompozit & 4.95 & yok & yok & var & $50-56$ \\
\hline \multirow{2}{*}{6} & \multirow{2}{*}{5} & 118 & 1000 & 1000 & saf kompozit & 4.93 & yok & yok & var & $42-48$ \\
\hline & & & & & katk1lı kompozit & 4.94 & yok & yok & var & $50-56$ \\
\hline 7 & 5 & 140 & 1000 & 200 & saf kompozit & 4.93 & yok & yok & yok & $42-48$ \\
\hline & & & & & katk1lı kompozit & 4.95 & var & yok & yok & $50-56$ \\
\hline 8 & 5 & 140 & 1000 & 600 & saf kompozit & 4.87 & var & yok & var & $42-48$ \\
\hline 8 & & 140 & 1000 & 000 & katk1lı kompozit & 4.9 & var & yok & var & $50-56$ \\
\hline 0 & 5 & 140 & 1000 & 1000 & saf kompozit & 4.78 & var & yok & var & $42-48$ \\
\hline 9 & 3 & 140 & 1000 & 1000 & katk1lı kompozit & 4.82 & yok & yok & var & $50-56$ \\
\hline
\end{tabular}


Ø5mm matkap kullanılarak elde edilen deliklerin matkap çapından küçük olduğu; matkap çapına en yakın delik ölçüsünün $118^{\circ}$ matkap ile sağlandığı tespit edildi. Fener mili devri değeri sabit tutularak ilerleme değeri arttıkça delik çapı ölçüsünün azaldığı görüldü (Şekil.7).

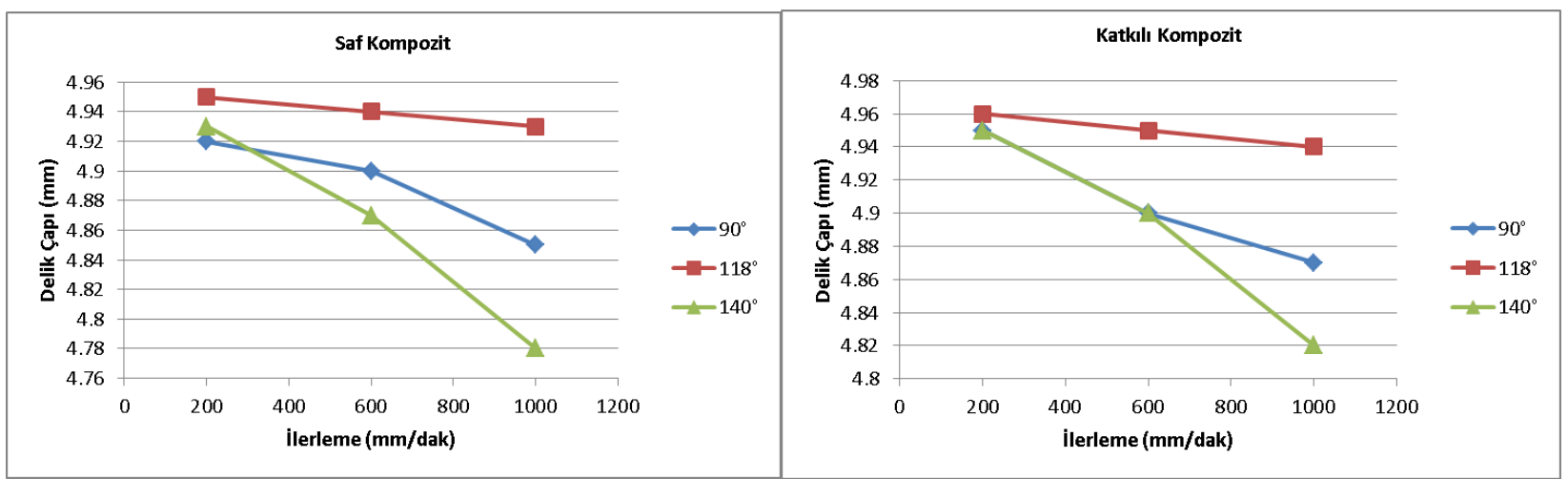

Şekil 7. Matkap nokta açısı ve ilerleme oranına bağlı delik çapı

Delaminasyon her iki kesme parametresi ile artar, bu da kompozit delaminasyonun daha yüksek kesme hızı (fener mili devri) ve daha yüksek ilerleme değerleri ile daha büyük olduğu anlamına gelir $[17,22]$.

\section{Sonuçlar}

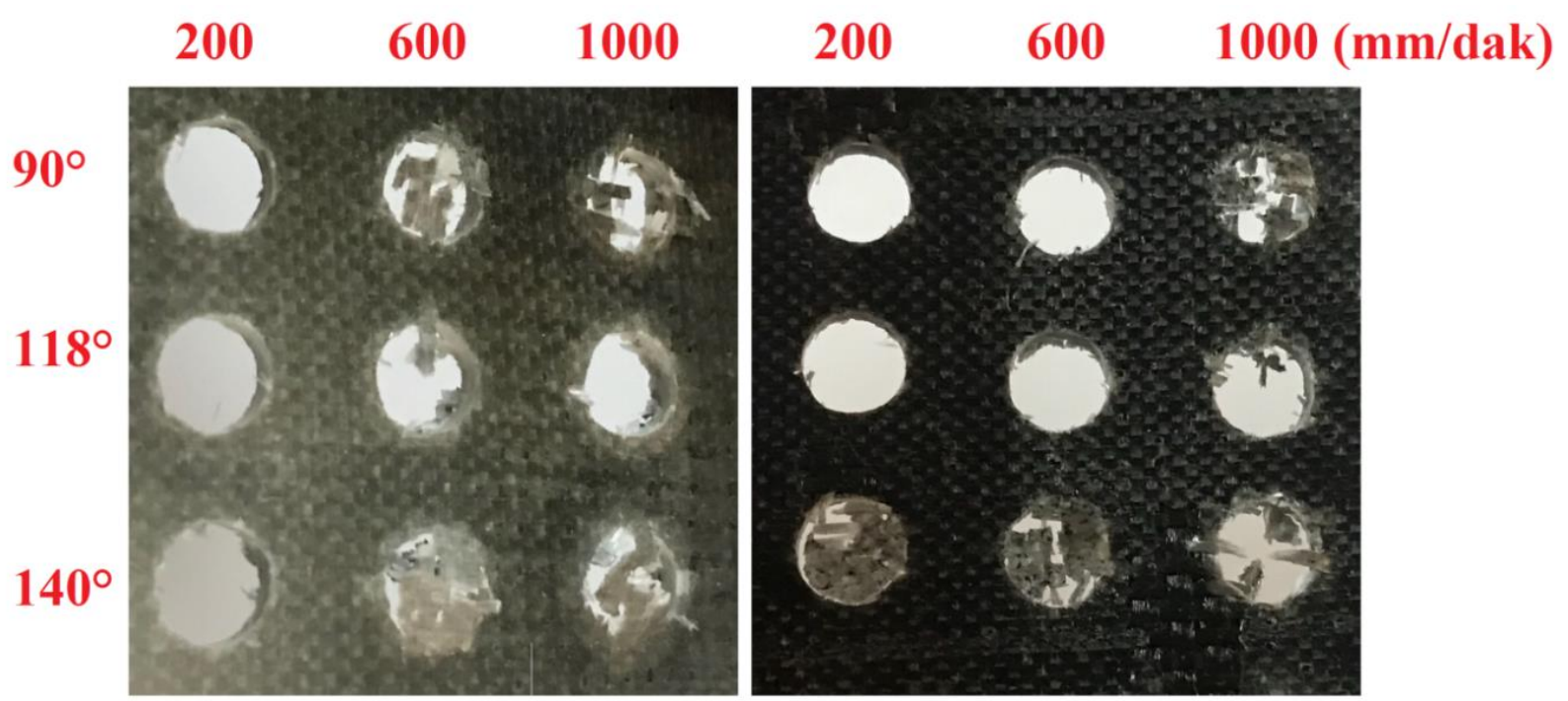

Şekil 8. ÇCKNT katkısız ve \% 0.1 katkılı kompozit plakaların delme sonrası çapaklanması

$\checkmark \quad$ Sabit $1000 \mathrm{dev} /$ dak tezgah devri ile $200 \mathrm{~mm} /$ dak ilerleme değerlerinde $90^{\circ}$ ve $118^{\circ}$ matkap uçları kullanılarak yapılan delme işleminde giriş ve çıkış kısımlarında çapaklanma görülmedi, $140^{\circ}$ matkap ucu ile yapılan delik delme işleminde katkılı kompozit tabaka delik çıkışında blok şeklinde delaminasyon görüldü. 
$\checkmark \quad$ Sabit $1000 \mathrm{dev} /$ dak tezgah devri ile $600 \mathrm{~mm} /$ dak ve $1000 \mathrm{~mm} /$ dak ilerleme değerlerinde $90^{\circ}$ ve $118^{\circ}$ matkap uçları kullanılarak yapılan delme işleminde giriş ve çıkış kısımlarında çapaklanma görüldü, $140^{\circ}$ matkap ucu ile yapılan delik delme işleminde giriş ve çıkış kısımlarında yoğun çapaklanma görüldü.

$\checkmark \quad$ En uygun çapaksız delme operasyonu $118^{\circ}$ matkap kullanımı; 1000 dev/dak tezgah devri ve $200 \mathrm{~mm} /$ dak ilerleme parametreleri ile elde edildi.

$\checkmark \quad$ Yüksek ilerleme değeri ve $140^{\circ}$ matkap ucu ile delme işleminde Nano partikül katkılı kompozit malzemenin delik çıkışında blok şeklinde delaminasyon görülürken, ÇCKNT katkısı bulunmayan kompozit plakada delik çıkışında parçalanma şeklinde delaminasyon oldu. ÇCKNT katkısının kompozit yüzeyindeki epoksi karışımında bağlayıcı olduğu görüldü.

$\checkmark \quad$ Matkap ucu açısı arttıkça çapaklanma arttı, sabit tezgah devri değeri ile matkap ucu açısı ve ilerleme değeri arttıkça delaminasyon arttı.

$\checkmark \quad$ Katkılı ve katkısız kompozit plakalardaki en belirgin delaminasyon $140^{\circ}$ matkap ucu ile $1000 \mathrm{dev} /$ dak tezgah devri ve $1000 \mathrm{~mm} /$ dak ilerlemede görüldü.

$\checkmark \quad$ Nano partikül takviyeli ve takviyesiz kompozit plakada en yoğun çapaklanma; 1000 tezgah devri ve $1000 \mathrm{~mm} /$ dak ilerleme ile $90^{\circ}$ matkap ucunda görüldü.

$\checkmark \quad \% 0.1$ ÇCKNT katkı maddesi ile üretilen kompozit malzemelerin katkısız tabakalara göre daha güçlü olduğu tespit edildi. Nanopartiküller ile düşük yoğunluklu, yüksek elastik modüle ve çekme dayanımına sahip nano kompozitler elde edildi.

\section{Kaynaklar}

[1] Mazumdar, S. K. Composites Manufacturing-Materials, Product and Process Engineering; 2002.p.13-19.

[2] Abrao, A. M., Faria, P. E., Rubio, J. C., Reis, P., \& Davim, J. P. Drilling of fiber reinforced plastics: A review. Journal of Materials Processing Technology 2007;186(1-3),1-7

[3] Liu, D., Tang, Y., \& Cong, W. L. A review of mechanical drilling for composite laminates. Composite structures 2012;94(4), 1265-1279.

[4] Singh, A. P., Sharma, M., \& Singh, I. A review of modeling and control during drilling of fiber reinforced plastic composites. Composites Part B: Engineering 2013;47, 118-125.

[5] Sankar, B. R., Umamaheswarrao, P., Reddy, A. A., \& Kumar, P. K. Drilling of composite laminates: a review. J Basic Appl Eng Res 2014;1(3), 19-24.

[6] Bonnet, C., Poulachon, G., Rech, J., Girard, Y., \& Costes, J. P. CFRP drilling: Fundamental study of local feed force and consequences on hole exit damage. International Journal of Machine Tools and Manufacture 2015;94, 57-64.

[7] Ghafarizadeh, S., Chatelain, J. F., \& Lebrun, G. Finite element analysis of surface milling of carbon fiber-reinforced composites. The International Journal of Advanced 
Manufacturing Technology 2016; 87(1-4), 399-409.

[8] Ismail, S. O., Dhakal, H. N., Popov, I., \& Beaugrand, J. Comprehensive study on machinability of sustainable and conventional fibre reinforced polymer composites. Engineering Science and Technology, an International Journal 2016;19(4), 2043-2052.

[9] Panchagnula, K. K., \& Palaniyandi, K. Drilling on fiber reinforced polymer/nanopolymer composite laminates: a review. Journal of materials research and technology 2018;7(2), 180-189.

[10] Mallick, P. K. Fiber-reinforced composites: materials, manufacturing, and design. CRC press; 2007.p.6-21.

[11] Panchagnula, K. K., \& Palaniyandi, K. Drilling on fiber reinforced polymer/nanopolymer composite laminates: a review. Journal of materials research and technology 2018;7(2), 180-189.

[12] Coleman, J. N., Khan, U., Blau, W. J., \& Gun'ko, Y. K. (2006). Small but strong: a review of the mechanical properties of carbon nanotube-polymer composites. Carbon, 44(9), 1624-1652.

[13] Yang, C. K., Lee, Y. R., Hsieh, T. H., Chen, T. H., \& Cheng, T. C. Mechanical property of multiwall carbon nanotube reinforced polymer composites. Polymers and Polymer Composites 2018; 26(1), 99-104.

[14] Marques, A. T., Durão, L. M., Magalhães, A. G., Silva, J. F., \& Tavares, J. M. R. Delamination analysis of carbon fibre reinforced laminates: evaluation of a special step drill. Composites Science and Technology 2009; 69(14), 2376-2382.

[15] Durão, L. M. P., Gonçalves, D. J., Tavares, J. M. R., de Albuquerque, V. H. C., Vieira, A. A., \& Marques, A. T. Drilling tool geometry evaluation for reinforced composite laminates. Composite structures 2010; 92(7), 1545-1550.

[16] Liu, D., Tang, Y., \& Cong, W. L. A review of mechanical drilling for composite laminates. Composite structures 2012; 94(4), 1265-1279.

[17] Davim, J. P., \& Reis, P. Drilling carbon fiber reinforced plastics manufactured by autoclave - experimental and statistical study. Materials \& design 2003; 24(5), 315-324.

[18] Abrao, A. M., Rubio, J. C., Faria, P. E., \& Davim, J. P. The effect of cutting tool geometry on thrust force and delamination when drilling glass fibre reinforced plastic composite. Materials \& Design 2008; 29(2), 508-513.

[19] Tsao, C. C., \& Hocheng, H. Effect of tool wear on delamination in drilling composite materials. International journal of mechanical sciences 2007; 49(8), 983-988.

[20] Hocheng, H., \& Tsao, C. C. Comprehensive analysis of delamination in drilling of composite materials with various drill bits. Journal of materials processing technology 2003; 140(1-3), 335-339.

[21] Mohan, N. S., Kulkarni, S. M., \& Ramachandra, A. Delamination analysis in drilling process of glass fiber reinforced plastic (GFRP) composite materials. Journal of Materials Processing Technology 2007; 186(1-3), 265-271.

[22] Davim, J. P., Reis, P., \& Antonio, C. C. Experimental study of drilling glass fiber reinforced plastics (GFRP) manufactured by hand lay-up. Composites Science and Technology 2004; 64(2), 289-297.

[23] Palanikumar, K., Campos Rubio, J., Abrao, A. M., Esteves Correia, A., \& Davim, J. P. Influence of drill point angle in high speed drilling of glass fiber reinforced plastics. Journal of composite Materials 2008; 42(24), 2585-2597. 